\title{
Study on estimation of creep behaviour of concrete at early age considering temperature effect
}

\author{
Kayo Ohashi ${ }^{1 *}$, Jun-ichi Arai ${ }^{2}$, and Toshiaki Mizobuchi ${ }^{3}$ \\ ${ }^{1}$ Student of master course, Department of Civil and Environmental Engineering, Hosei University Graduate School, Japan \\ ${ }^{2}$ Student of doctoral course, Department of Civil and Environmental Engineering, Hosei University Graduate School, Japan \\ ${ }^{3}$ Professor, Department of Civil and Environmental Engineering, Hosei University, Japan
}

\begin{abstract}
Clarifying the creep behaviour of concrete at early age not only improves the accuracy of temperature stress analysis but also contributes to prediction accuracy and control measures in cracks caused by thermal stress. However, most past researches on creep behaviour were investigated after 28 days. Currently, it is difficult to accurately perceive the creep behaviour of concrete at an early age in the test method of creep which is generally carried out. Therefore, it is necessary to evaluate the creep behaviour of concrete at early age and to establish a convenient test method to estimate the creep behaviour. Therefore, in this study, experiments were carried out for concrete at early age within one week. As the result of the experiments, it was shown that the creep strain is proportional to the load stress of concrete at an early age and the strain of specific creep decreases as the loaded age increases. In addition, based on the experimental results, an estimation equation for creep strain at early age was proposed. Within the scope of this experimental result, it was confirmed that the estimation equation proposed in this study accurately represented the creep behaviour of concrete at early age.
\end{abstract}

\section{Introduction}

The purpose of this study was to clarify the creep behaviour of concrete at early age.

Thermal cracking caused by volume change during heat hydration of cement is not only an initial defect but also greatly affects durability of concrete structures. The thermal stress analysis is carried out in order to predict and control thermal cracking. However, the result of prediction of the thermal stress analysis may be different from results of stress behaviour in the existing structure. One of the cause is that the creep behaviour of concrete at early age has been clarified.

Most past research on creep behaviour has been investigated after 28 days. There are few studies on the creep behaviour of concrete at early age during heat hydration of cement. Among them, the estimation equation that can be used for the thermal stress analysis have been proposed for Morimoto's research [1], Yoshitake's research [2], Sakata's research [3], Ozawa's research [4], and Iriya's research [5]. However, the estimation equation of creep strain at early age that comprehensively evaluated the influence factor including stress/strength ratio, water to cement ratio, and curing temperature has not been proposed so far.

Therefore, in this study, experiments were carried out for concrete at early age within one week to acquire the data for the creep behaviour of concrete at early age. In addition, based on the experimental results, the estimation equation of creep strain at early age was proposed to clarify the creep behaviour of concrete.

\section{Outline of Experiment}

\subsection{Case studied}

In this study, the subject of investigation was creep of concrete made with Portland blast-furnace slag cement type B (hereinafter referred to as BB) in JIS (Japanese Industrial Standards). The curing temperature was constant at $20^{\circ} \mathrm{C}, \quad 30^{\circ} \mathrm{C}, \quad 40{ }^{\circ} \mathrm{C}$, and $50^{\circ} \mathrm{C}$. The stress/strength ratio was set to three levels of $0.2,0.3$, and 0.4 . For the $20^{\circ} \mathrm{C}$ curing temperature, the water to cement ratio was set to three levels of $0.45,0.5$ and 0.6. For the other curing temperatures, the water to cement ratio was set to 0.5 . In this experiment, the target slump was $12 \pm 1.5 \mathrm{~cm}$ in consideration of workability, and the target air content was $4.5 \pm 1.0 \%$. Table 1 shows the cases studied and Table 2 shows the mix proportion of concrete.

Table 1. Mix proportion of concrete.

\begin{tabular}{|c|c|c|c|c|c|c|}
\hline \multirow{2}{*}{$\begin{array}{c}\text { Kinds } \\
\text { of } \\
\text { cement }\end{array}$} & $\begin{array}{c}\text { Curing } \\
\text { tem- } \\
\text { perature } \\
\left({ }^{\circ} \mathrm{C}\right)\end{array}$ & $\mathrm{W} / \mathrm{C}$ & $\mathrm{W}$ & $\mathrm{C}$ & $\mathrm{S}$ & $\mathrm{G}$ \\
\cline { 5 - 8 } & & 0.45 & 157 & 349 & 775 & 1017 \\
\hline \multirow{4}{*}{$\mathrm{BB}$} & 20 & 0.5 & 154 & 308 & 798 & 1043 \\
\cline { 3 - 7 } & 0.6 & 154 & 257 & 815 & 1072 \\
\cline { 2 - 7 } & 30,40, & 0.5 & 157 & 314 & 771 & 1053 \\
\hline
\end{tabular}

Table 2. Study cases

*orresponding author: kayo.ohashi.7f@stu.hosei.ac.jp 


\begin{tabular}{|c|c|c|c|c|}
\hline $\begin{array}{l}\text { Kinds } \\
\text { of } \\
\text { cement }\end{array}$ & $\begin{array}{c}\text { Curing } \\
\text { temperature } \\
\left({ }^{\circ} \mathrm{C}\right)\end{array}$ & $\mathrm{W} / \mathrm{C}$ & $\begin{array}{l}\text { Age of } \\
\text { testing } \\
\text { (days) }\end{array}$ & $\begin{array}{l}\text { Stress/strength } \\
\text { ratio }\end{array}$ \\
\hline \multirow{4}{*}{$\mathrm{BB}$} & 20 & $\begin{array}{l}45 \\
50 \\
60\end{array}$ & $\begin{array}{l}1 \\
3 \\
5 \\
7\end{array}$ & \multirow{4}{*}{$\begin{array}{l}0.2 \\
0.3 \\
0.4\end{array}$} \\
\hline & 30 & \multirow{3}{*}{50} & \multirow{3}{*}{$\begin{array}{l}3 \\
5 \\
7\end{array}$} & \\
\hline & 40 & & & \\
\hline & 50 & & & \\
\hline
\end{tabular}

\subsection{Experimental method}

In this study, experiments using the convenient creep test equipment developed in our laboratory were carried out for concrete at early age. Fig. 1 shows details of the creep test equipment used for loading. As the method of experiment, the steel rod is pulled by the jack with a hole in the center, and the nut is tightened when the predetermined load is reached.

The concrete is stressed using the force of the steel rod as it tries to return to its original length. In the experiment, the cases shown in Table 2 were carried out using one specimen for each age and stress/strength ratio. The creep strain was measured by the strain gauge attached the steel rod. Fig. 2 shows a schematic of the test object to be loaded. The details of specimen used in the experiment is shown in Fig. 2.

Also, the compressive test was carried out using oil pressure type universal testing machine to find the stress/strength ratio. The compressive test was carried out using three specimens. The specimen is a cylinder with a diameter of $100 \mathrm{~mm}$ and a height of $200 \mathrm{~mm}$. Table 3 shows loading stress.

\section{Experimental results}

\subsection{Relationship between water to cement ratio and strain of specific creep}

Table 4 shows all experimental results. In Table 4, the case displayed as “-” didn't have a result because the experiment failed.

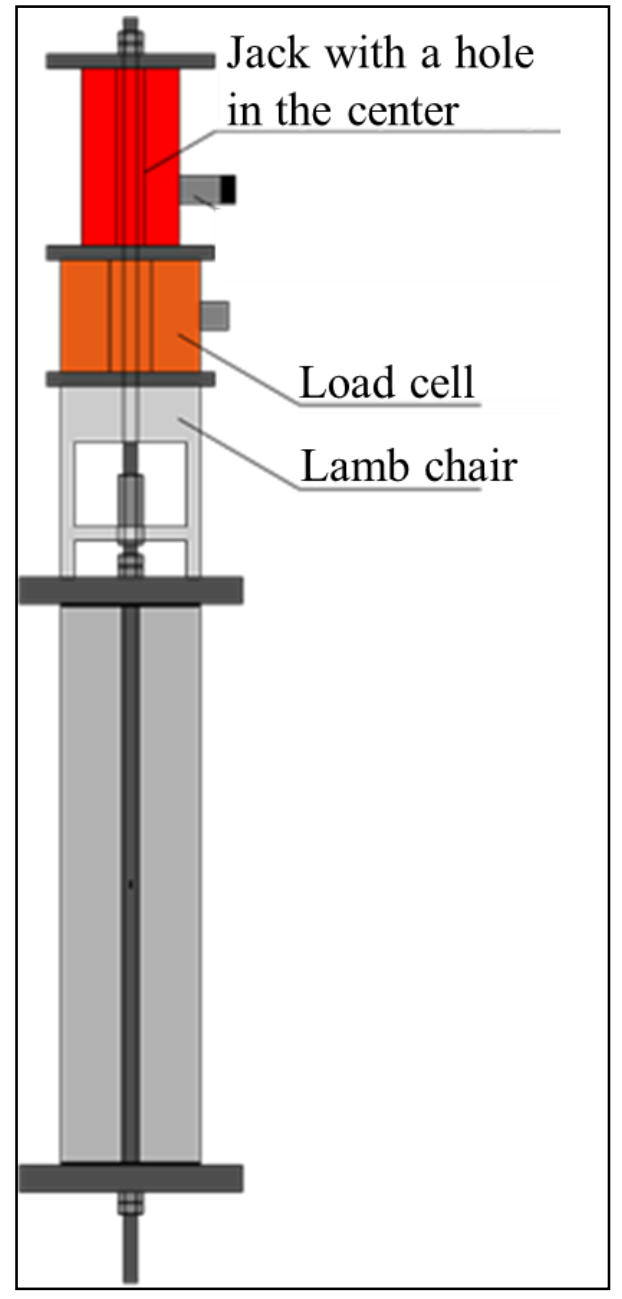

Fig. 1. Detail of the creep test equipment.
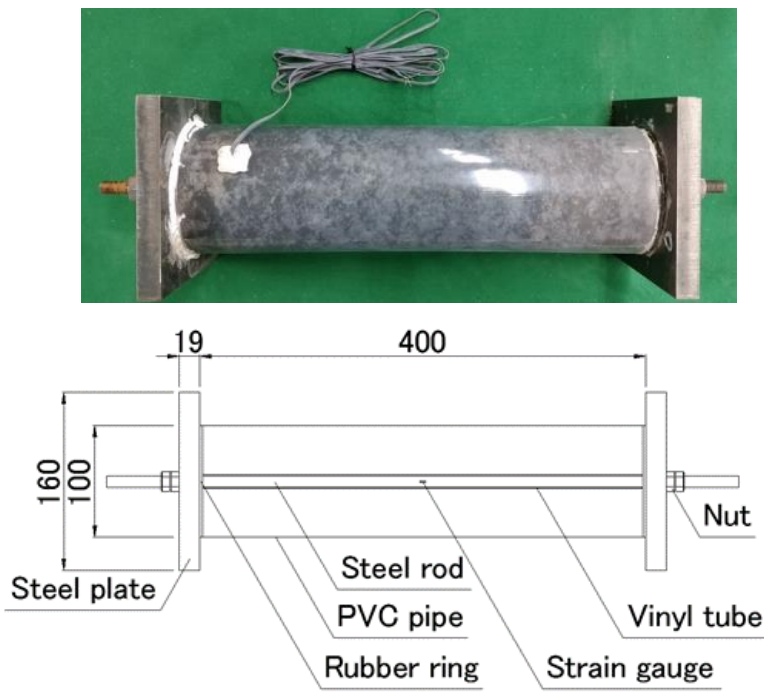

Fig. 2. Details of specimen. 
Table 3. Loading stress

\begin{tabular}{|c|c|c|c|c|c|}
\hline \multirow{3}{*}{$\begin{array}{l}\text { Curing } \\
\text { tempera- } \\
\text { ture }\left({ }^{\circ} \mathrm{C}\right)\end{array}$} & \multirow{3}{*}{$\mathrm{W} / \mathrm{C}$} & \multirow{3}{*}{$\begin{array}{l}\text { Age of } \\
\text { testing } \\
\text { (days) }\end{array}$} & \multicolumn{3}{|c|}{ Loading stress $(\mathrm{kN})$} \\
\hline & & & \multicolumn{3}{|c|}{ Stress/strength ratio } \\
\hline & & & 0.2 & 0.3 & 0.4 \\
\hline \multirow{12}{*}{20} & \multirow{4}{*}{0.45} & 1 & 8.2 & 15.2 & 16.2 \\
\hline & & 3 & 26.2 & 40.2 & 53.6 \\
\hline & & 5 & 35.5 & 52.2 & 70.9 \\
\hline & & 7 & 37.0 & 54.7 & 73.9 \\
\hline & \multirow{4}{*}{0.5} & 1 & 5.7 & 9.1 & 12.5 \\
\hline & & 3 & 20.7 & 32.0 & 42.8 \\
\hline & & 5 & 27.9 & 41.9 & 55.9 \\
\hline & & 7 & 44.7 & 62.0 & 83.2 \\
\hline & \multirow{4}{*}{0.6} & 1 & 4.4 & 6.5 & 10.0 \\
\hline & & 3 & 15.7 & 22.7 & 31.2 \\
\hline & & 5 & 23.1 & 35.0 & 46.2 \\
\hline & & 7 & 25.7 & 42.0 & 54.8 \\
\hline \multirow{3}{*}{30} & \multirow{9}{*}{0.5} & 3 & 21.9 & 33.8 & 43.7 \\
\hline & & 5 & 27.5 & 41.2 & 55.0 \\
\hline & & 7 & 33.4 & 50.0 & 66.7 \\
\hline \multirow{3}{*}{40} & & 3 & 22.3 & 33.4 & 44.5 \\
\hline & & 5 & 30.1 & 45.2 & 60.2 \\
\hline & & 7 & 37.3 & 55.9 & 74.6 \\
\hline \multirow{3}{*}{50} & & 3 & 18.0 & 27.0 & 36.0 \\
\hline & & 5 & 29.4 & 44.1 & 58.8 \\
\hline & & 7 & 34.3 & 51.5 & 68.7 \\
\hline
\end{tabular}

Fig. 3 shows one case of the relationship between water to cement ratio and strain of specific creep (curing temperature: $20^{\circ} \mathrm{C}$, the age of testing: 3days, stress/strength ratio: 0.4). For water to cement ratios between 0.45 and 0.5 , the strain of specific creep was nearly constant. However, for water to cement ratios between 0.5 and 0.6 , the strain of specific creep increased by approximately $15 \times 10^{-6} / \mathrm{MPa}$. This result shows, under the conditions of this experiment, when the water to cement ratio is $50 \%$ or more, the strain of specific creep increases.

\subsection{Relationship between stress/strength ratio and strain of specific creep}

Fig. 4 shows relationship between stress/strength ratio and strain of specific creep. Hiramoto's research [6] shows that when the ratio of stress/strength is less than 0.5 , the strain of specific creep is constant since the creep strain is proportional to the load stress. Fig. 3 shows that the strain of specific creep is constant when water to cement ratios is $50 \%$. Therefore, the creep strain is also proportional to the load stress in this study too.
Table 4. All experimental results

\begin{tabular}{|c|c|c|c|c|c|}
\hline \multirow{3}{*}{$\begin{array}{l}\text { Curing } \\
\text { tempera- } \\
\text { ture }\left({ }^{\circ} \mathrm{C}\right)\end{array}$} & \multirow{3}{*}{$\mathrm{W} / \mathrm{C}$} & \multirow{3}{*}{$\begin{array}{l}\text { Age of } \\
\text { testing } \\
\text { (days) }\end{array}$} & \multicolumn{3}{|c|}{$\begin{array}{c}\text { Specific creep strain }\left(10^{-}\right. \\
6 / \mathrm{Mpa})\end{array}$} \\
\hline & & & \multicolumn{3}{|c|}{ Stress/strength ratio } \\
\hline & & & 0.2 & 0.3 & 0.4 \\
\hline \multirow{12}{*}{20} & \multirow{4}{*}{0.45} & 1 & 106.7 & 79.4 & 53.1 \\
\hline & & 3 & 23.4 & 20.8 & 21.1 \\
\hline & & 5 & 16.0 & 15.7 & 14.3 \\
\hline & & 7 & 12.7 & 12.7 & 13.2 \\
\hline & \multirow{4}{*}{0.5} & 1 & 88.6 & 65.2 & 34.8 \\
\hline & & 3 & 18.4 & 20.5 & 20.6 \\
\hline & & 5 & 14.5 & 14.7 & 15.7 \\
\hline & & 7 & 14.7 & 16.0 & 15.9 \\
\hline & \multirow{4}{*}{0.6} & 1 & 148.9 & 111.4 & 85.1 \\
\hline & & 3 & 37.3 & 32.8 & 33.1 \\
\hline & & 5 & 21.7 & 25.1 & 22.0 \\
\hline & & 7 & 14.5 & 13.1 & 15.6 \\
\hline \multirow{3}{*}{30} & \multirow{9}{*}{0.5} & 3 & - & 1.4 & 9.5 \\
\hline & & 5 & 13.1 & 10.6 & 8.0 \\
\hline & & 7 & - & 7.1 & 7.9 \\
\hline \multirow{3}{*}{40} & & 3 & 25.4 & 14.6 & 35.4 \\
\hline & & 5 & 29.0 & 28.2 & 22.6 \\
\hline & & 7 & 14.1 & 15.7 & 20.2 \\
\hline \multirow{3}{*}{50} & & 3 & - & 139.3 & 133.4 \\
\hline & & 5 & 97.2 & - & - \\
\hline & & 7 & 105.2 & 97.7 & 96.5 \\
\hline
\end{tabular}

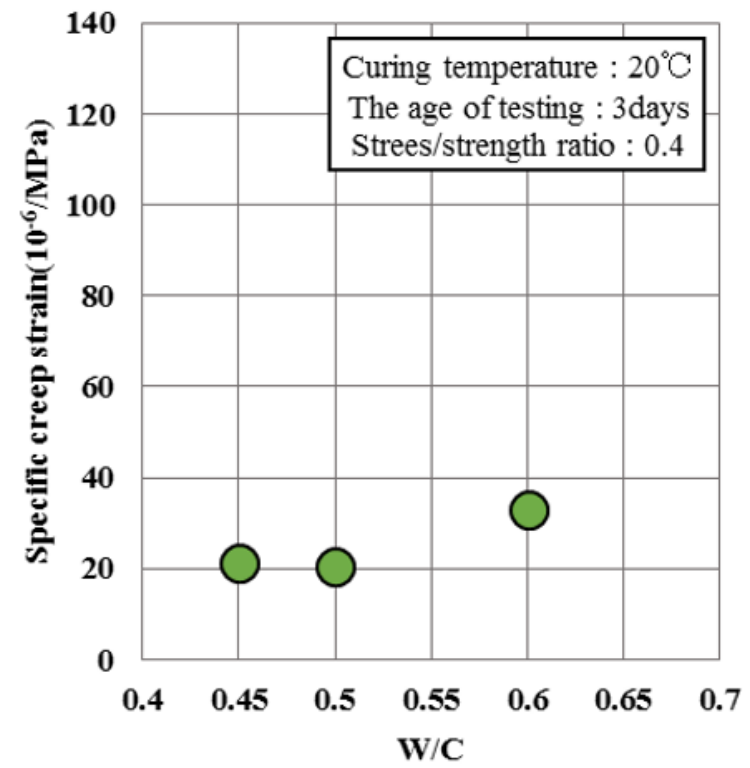

Fig. 3. Relationship between water to cement ratio and strain of specific creep (curing temperature: $20^{\circ} \mathrm{C}$, the age of testing: 3days, stress/strength ratio: 0.4 ).

Also, Fig. 4 shows that the specific creep increases when curing temperature is $50^{\circ} \mathrm{C}$. The creep strain is caused by 
the water movement in the concrete [7]. Therefore, the reason why the specific creep increases when curing temperature is $50^{\circ} \mathrm{C}$ is the water movement in the concrete becomes active at high temperature. The same goes for Fig. 5.

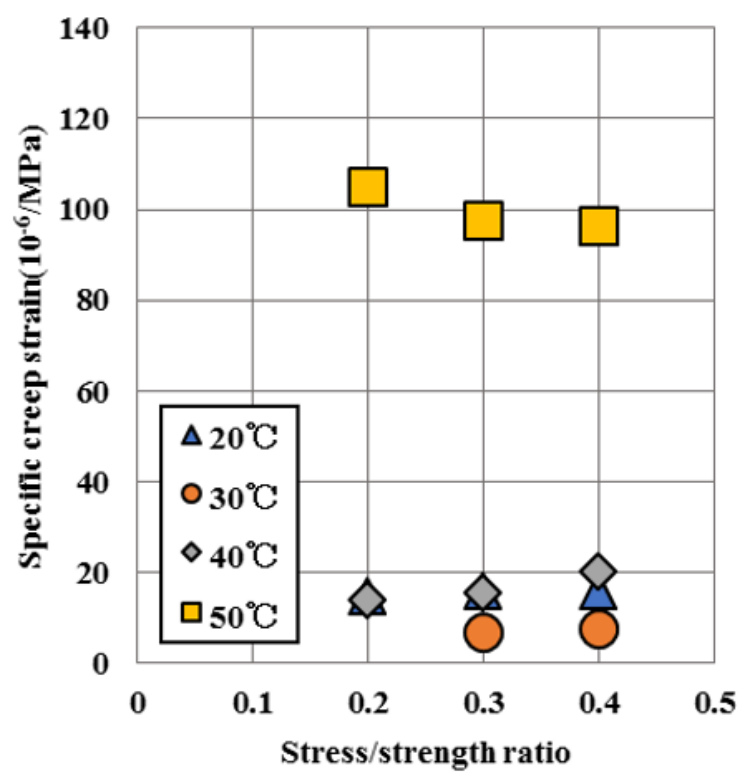

Fig. 4. Relationship between stress/strength ratio and strain of specific creep.

\subsection{Relationship between loaded age and strain of specific creep}

Fig. 5 shows relationship between loaded age and strain of specific creep. The strain of specific creep decreases as the loaded age increases. This is because the strength development of concrete progresses as the age of concrete increases. And the strain of specific creep decreases faster as the curing temperature is higher, since the higher the curing temperature, the faster the strength development of the concrete. The same tendency was shown in Hiramoto's research. [6]

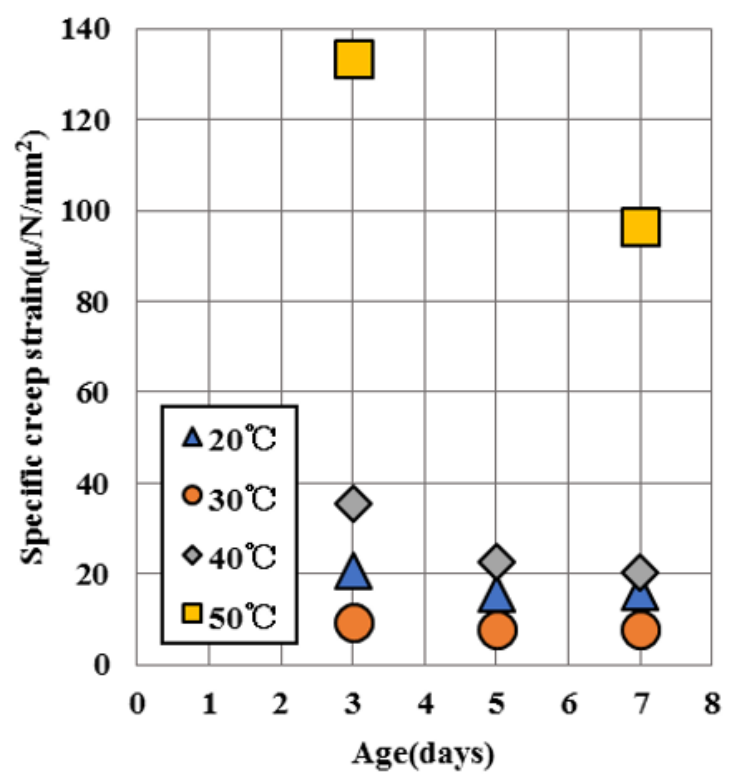

Fig. 5. Relationship between loaded age and strain of specific creep.

\subsection{Relationship between curing temperature and strain of specific creep}

Fig. 6 shows the relationship between curing temperature and strain of specific creep. The strain of specific creep increases as the curing temperature increases. In Hattori's research [8], the creep behaviour of concrete in early age has the tendency that the water movement in the concrete becomes active at high temperature and creep strain increases. This results of the experiments shows the same tendency as Hattori's research. [8]

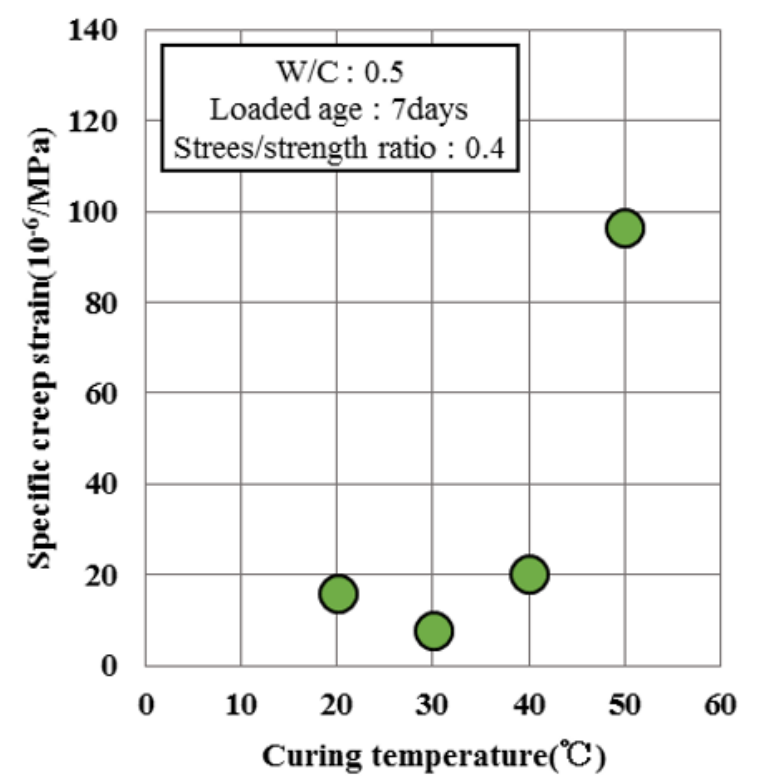

Fig. 6. Relationship between curing temperature and strain of specific creep.

\subsection{The estimation equation of creep strain in early age concrete}

Since the experimental results are same tendency shown in past research, the experimental results are assumed to be correct, and the estimation equation was created to match the experimental results. The estimation equation was created based on the CEP-FIP model code 90 [9].The estimation equation of creep strain at early age is shown below.

$$
\begin{gathered}
\varepsilon=\alpha *\left[1 /\left(1+0.01 * \exp \left\{-0.01 *\left(t-t_{0}\right)\right\}\right)\right] \\
* \varepsilon^{\infty} *\left[1-\exp \left\{-\beta *\left(t-t_{0}\right)^{0.5}\right\}\right] \\
\alpha=\exp \left(T^{0.7}\right) * 9.51 * 10^{-7}+0.654 \\
\varepsilon_{t 14}=\{0.1 * \exp (W / C * 10)+10\} *\{ \\
\left.4.66 * \exp \left(-t_{0}\right)+0.828\right\} \\
\beta=0.01 * \exp \left(0.457 * t_{0}\right)+0.661
\end{gathered}
$$

here

$\varepsilon:$ the strain of specific creeep $\left(10^{-6} / \mathrm{MPa}\right)$ 
$t_{0}:$ loaded age (days)

$\mathrm{t}:$ age (days)

$\mathrm{T}$ : curing temperature $\left({ }^{\circ} \mathrm{C}\right)$

$\varepsilon_{\mathrm{t} 14}$ : the strain of specific creep at management materials age 14 days $\left(10^{-6} / \mathrm{MPa}\right)$

$\mathrm{W} / \mathrm{C}$ : water to cement ratio

$\alpha, \beta$ : coefficient

One case of the comparison of experimental results and the estimation values calculated by equation (1) to (4) are shown in Fig. 7. In addition, the estimation values calculated by the design equation from the design standards [10] are also shown in Fig. 7 too. From Fig. 7, within the scope of this study, it was confirmed that the estimation equation proposed in this study is able to estimate the creep behaviour of concrete at early age with relatively high accuracy than the design equation from the design standards [10].

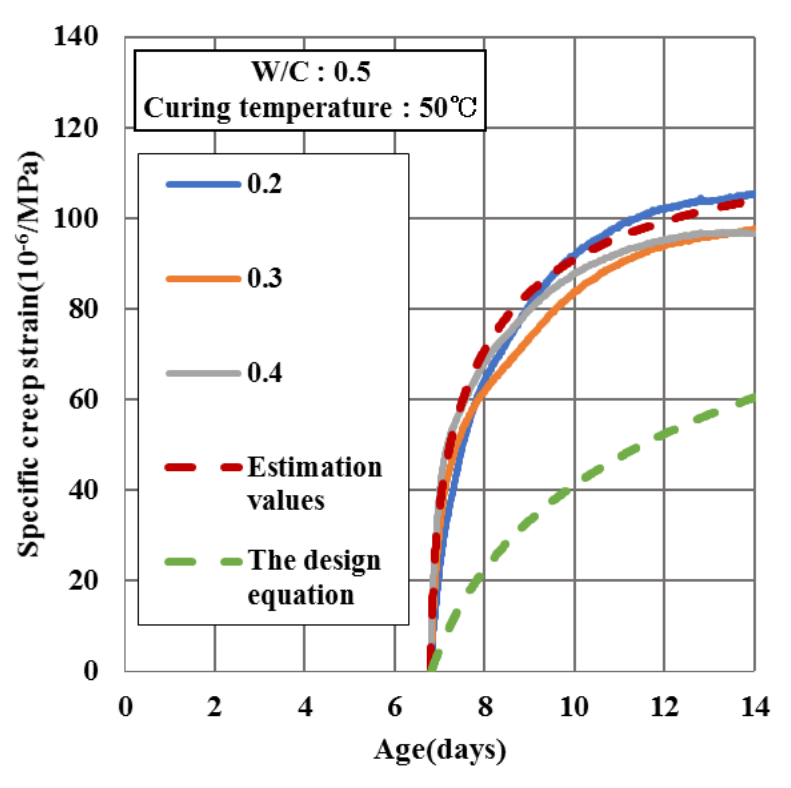

Fig. 7. Comparison of experimental results, estimation values calculated by equation (1) to (4) and the design equation.

Fig. 8 shows comparison of the experimental results and the estimation values calculated by equation (1) to (4) at an age of 10 days after loading. Within the scope of this study, it was also confirmed that the estimation equation proposed in this study accurately represented the creep behaviour of concrete at early age, even when the curing temperature and the stress/strength ratio are changed.

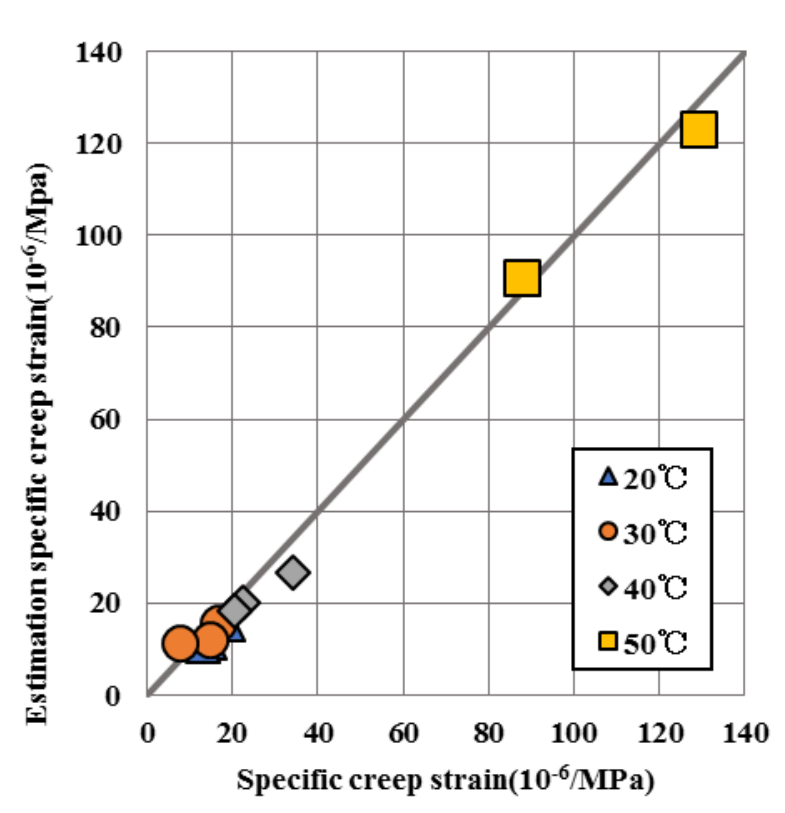

Fig. 8. Comparison of experimental results and estimation values calculated by equation (1) to (4) at age of 10 days

\section{Conclusions}

In this study, experiments using the convenient creep test equipment developed in our laboratory were carried out for concrete at early age within one week and we acquired the data for the creep behaviour of concrete at early age. In addition, based on the experimental results, the estimation equation of creep strain at early age was proposed to clarify the behaviour of young concrete. The results are shown below.

1. When water to cement ratio is $60 \%$ or more, the strain of specific creep increases.

2. The creep strain is proportional to the load stress.

3. The strain of specific creep decreases as the loaded age increases. And the strain of specific creep decreases faster as the curing temperature is higher.

4. The strain of specific creep increases as the curing temperature increases.

5. The result of experiments using the convenient creep test equipment developed in our laboratory shows the same tendency as past research.

6. The estimation equation of creep strain at early age we propose makes it possible to estimate creep strain at early age.

\section{References}

1. H. Morimoto, T. Iwamoto, T. Kurihara, K. Koyanagi, Compressive and tensile creep properties of concrete at early age, Cement Science and Concrete Technology, No.47, pp356-359, (1993)

2. I. Yoshitake, H. Nakamura, S. Nagai, S. Hamada, A Study on the Tension Creep Equation During Hydration in the Early Age, Journal of Japan Society of Civil Engineers, No.634/V-45, pp43-53, (1999) 
3. K. Sakata, K. Ayano, Study on non-linear creep prediction equation of concrete, Journal of japan society of civil engineers, No.451/V-17, pp179-188, (1992)

4. M. Ozawa, R. Kunimori, K. kurumada, H. morimoto, On the Creep Properties of High Strength Concrete at Early Ages, Proceedings of the Japan Concrete Institute, Vol. 22, No.2, (2000)

5. T. Goto, T. Uehara, H. Umehara, Studies on Creep Behavior of Early Age Concrete, Proceedings of the Japan Concrete Institute, vol.17, No.1, (1995)

6. M. Hiramoto, K. Iriya, S. Gupta, H. Umehara, Age and Stress Dependence of Creep in Concrete at Early Ages, Proceedings of the Japan Concrete Institute, vol.19, No.1, (1997)

7. T. Tanabe, Nonlinear analysis method and program of RC structure considering initial stress, Tokyo: Gihodo shuppan, (2004)

8. T. Hattori, K. Iriya, T. Uehara, H. Umehara, Study on Temperature Effects in Tensile Creep of Early Aged Concrete, Proceedings of the Japan Concrete Institute, vol.20, No.2, (1998)

9. CEB:CEB-FIP Model Code 1990, ComiteEuroInternational Du Beton, pp27-38, (1990)

10. JSCE Concrete Committee, Standard Specifications for Concrete Structures [Design] -2012, (2012) 